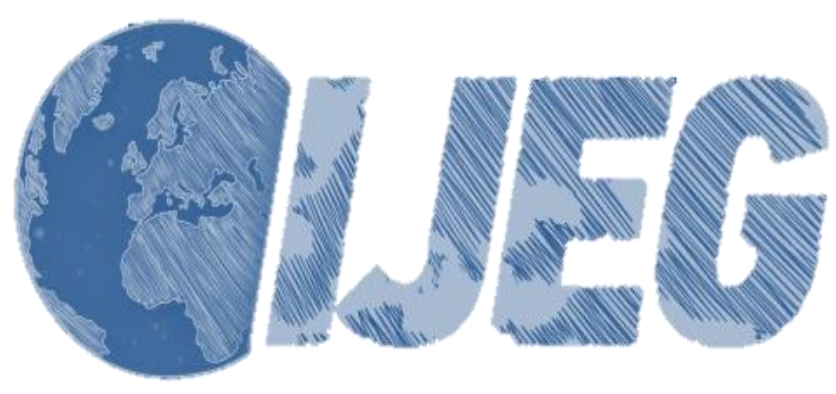

International Journal of Engineering and Geosciences (IJEG), Vol; 4, Issue; 2, pp. 063-070, June, 2019, ISSN 2548-0960, Turkey, DOI: 10.26833 ijeg. 443114

\title{
DETECTION OF ECOLOGICAL NETWORKS AND CONNECTIVITY WITH ANALYZING THEIR EFFECTS ON SUSTAINABLE URBAN DEVELOPMENT
}

\author{
Serdar Selim ${ }^{1}$, Nuster Demir *1 \\ ${ }^{1}$ Akdeniz University, Faculty of Science, Department of Space Science and Technologies, 07070, Antalya/TURKEY e- \\ mail: (serdarselim/nusretdemir@akdeniz.edu.tr)
}

ORCID 0000-0002-5631-6253; ORCID 0000-0002-8756-7127

*Corresponding Author, Received: 12/07/2018, Accepted: 11/09/2018

\begin{abstract}
Rapid urbanization is a leading process for the global environmental problems such as climate change, massive loss of natural habitats, an increase of air, water, soil quality and social troubles. Within the scope of elimination of these effects, detecting, preserving and managing a strategically planned ecological network can provide ecological, economic, social and cultural benefits. Specially, connectivity of landscape patches in urban areas is an important factor for urban ecosystem cycle. Ecological studies under these circumstances are concentrated in urban areas and strategies are being developed to create green systems by establishing links between green areas. In this study, a method based on the graph theory has been proposed to create ecological links between important landscape patches in the Chennai City and the effects of the created system on the city has been discussed. Firstly, a comprehensive database is created for Chennai in the GIS. And then, important urban landscape patches and connectivity are detected with use of Conefor software that enhances the quality of landscape patches and ensures that landscape connectivity is sustainable. With this scope, we used integral index of connectivity (IIC) index and the probability of connectivity (PC) index that have been known to show an enhanced performance for urban habitat conservation planning and change monitoring applications. Ultimately, the resulting findings are mapped in the GIS environment, and the ecological, social and cultural impacts of the system are discussed based on international literature.
\end{abstract}

Keywords: Urban ecology, Landscape connectivity, Green infrastructure, GIS 


\section{INTRODUCTION}

Along with the rapid urbanization and land cover changes in recent years, natural habitats became reduced in size and fragmented especially in developed and developing countries (Williams et al., 2009 and Hüse et al., 2016). The natural habitats are important for the citizens as well (Simsek et al., 2018) and GIS methods are useful to determine the spatial problems (Akar et.al, 2018; Memduhoglu and Basaraner, 2018). Habitat fragmentation and division of landscapes, reduce the connectivity between habitat patches by extending the distances between the remaining habitat stands, which lead to the loss of biodiversity in the long process (Bogyó et al., 2015 and Hüse et al., 2016). Thus preserving biodiversity and sustainability of landscape special in urban areas have a high priority in urban ecological planning (Talley et al., 2007 and Zipkin et al., 2009). Habitat connectivity is the most necessary and important factor that promotes the preservation of biodiversity in degraded landscapes by promoting gene flow and the expansion of individuals movement areas between populations (Lindborg et al., 2012 and Hüse et al., 2016). Besides, these habitat connections also support the sociocultural life in the city and increase the quality of life. In this context, especially in urban settlements, the evaluation of qualities of habitat patches and the determination of habitat connections are an important guide for future urban planning studies.

In a rapidly developing country such as India, the determination of the ecological characteristics of urban habitats is necessary for the future of Indian cities. As known, green spaces planning and accordingly management in urban areas up to now requires greater insights in socio-economical, socio-cultural, and ecological aspects that ensure a sustainable urban structure (Thompson, 2002; Govindarajulu, 2014). In this context, it is necessary to have information about the ecological structure of the Chennai City in India, which has entered into a process of rapid economic and cultural development, and to use this knowledge for the ecological development of the city. To reach mentioned targets above, the main target of the study is to detect the important landscape patches and connection of landscapes of Chennai city. This framework includes the detection of spatial elements (patch areas and sizes, ecological corridors, landscape matrix, etc.) (Govindarajulu, 2014). It is really important to connect the habitat patches (open green spaces such as parks, city garden, and urban forest) using corridors (green ways, river, and sides, tree-line roads etc.) to sustain ecological connectivity between landscape patches in landscape matrix. Landscape corridors are the most important parts of green space planning and management; and these corridors can be used to reduce the negative impact of landscape degradation (Majka et al., 2007). These corridors also support urban life and create interconnected open- green space systems called green infrastructure.

In generally, connectivity indexes have been used for determination of ecological connectivity. These connectivity indexes give accurate results quickly as integrated into the GIS software. It transformed and systematized the landscape structure that is complex and interactive, helping to describes the significance of every green space, and guiding urban and environmental planning for conservation of biodiversity and sustainable ecological development (Kong et al., 2010). In this study, Conefor Sensinode 2.2 software that can calculate the landscape connection has been used. Conefor software is known to exhibit a more advanced performance compared to other existing indexes with the new index (integral index of connectivity 'IIC', the probability of connectivity 'PC'). (Saura and Pascual-Hortal 2007, Saura and Rubio 2010, Saura et al., 2011). These indices are based upon mathematical graphs theory and measure the connections between habitat patches. These indices allow the assessment of linkages, connectivity, and availability of a habitat patch to other habitat patches. Thus, the landscape link is designed as a feature that determines and measures the number of patches available in a landscape matrix. The links do not assess whether the landscape patch is high or low quality, or whether it has strong ecological associations, but these links are an indication of whether the landscape patches are accessible (Saura and Torne, 2009).

This study, which was prepared to determine the habitat connections between selected landscape patches in the Chennai city and to provide ecological support to the city's future, will be an important data source for urban physical planning studies of the Chennai. Six landscape patches that affect the economic, cultural, social and ecological aspects of the city are selected and the connections between them are determined with help of remote sensing (RS) and geographical information systems (GIS). Then, these connections were evaluated based on landscape ecology and interpreted on the basis of landscape ecology to ensure sustainable urban development. Based on these results, we emphasize which patches are more important to the city.

\section{MATERIALS AND METHODS}

\subsection{Study area}

The second level headings should be in 10pt, bold, justified, and capitalized font. Leave one blank line both before and after the heading, respectively. Chennai is among the top five cities and is the capital of the Indian state of Tamil Nadu (N $13^{\circ} 5^{\prime} 0^{\prime \prime}$, E $80^{\circ} 16^{\prime} 0^{\prime \prime}$ ). It is located on the Coromandel Coast off the Bay of Bengal, it is one of the most important centers of the economy, education and culture in South India. Chennai has a flat and wide area in this context it expanded from $174 \mathrm{~km} 2$ to an area of $426 \mathrm{~km} 2$ dividing into three regions (North, South, and Central) which covers 200 wards in 2011 (Wikipedia, 2016). The climate of that region is tropical wet and dry. Maximum temperatures are around $35-40{ }^{\circ} \mathrm{C}$, minimum temperatures are around $19-25^{\circ} \mathrm{C}$ (IMD, 2010). Chennai shows a similar process of urbanization as in other major cities: increasing land use intensity and intensive pressure on natural areas (Fig 1). 


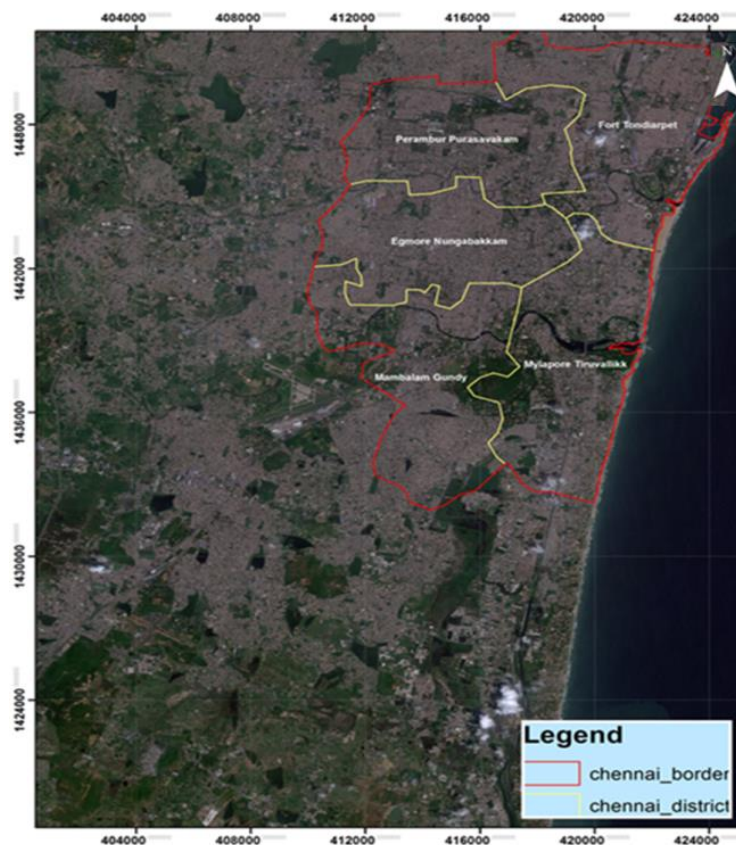

Figure 1. Location of study area

According to the official records of the year 2011, the city is home to 4,646,732 inhabitants (MUB, 2011). Chennai is one of the most visited cities in India because it has many historical and cultural riches, especially UNESCO's Mahabalipuram Heritage Site. In this context, the city visited more than 3 million tourists in 2011. Three long rivers and many lakes spread across the city attract ecologically interested tourists. (Wikipedia, 2016). These wetlands have unique ecology and endemic flora and fauna (Zanakiraman et al., 2013). A considerable part of the urban wetlands is thought to have been transformed, especially for agriculture and settlement. Since the beginning of the 20th century, the amount of wetlands in the Chennai has decreased from 150 to under 30 currently. The important wetlands include Ennore creek, Adyar Estuary, Korattur swamp, Adambakkam Ambattur and Chitlapakkam lakes, Madhavaram and Manali Jheels, Pulicat and Vyasarpadi lakes, Coovum and Otteri nullah, and Buckingham Canal. (Gubta and Nair, 2011; The Economist, 2015). The region has an important area ecologically. For the sustainability of the region, ecological characteristics must be preserved and maintained in the Chennai.

\subsection{Data}

In the study, six regions were selected which are important in terms of their ecological characteristics, affecting the city of Chennai ecologically, economically, socially and culturally (Fig 2).
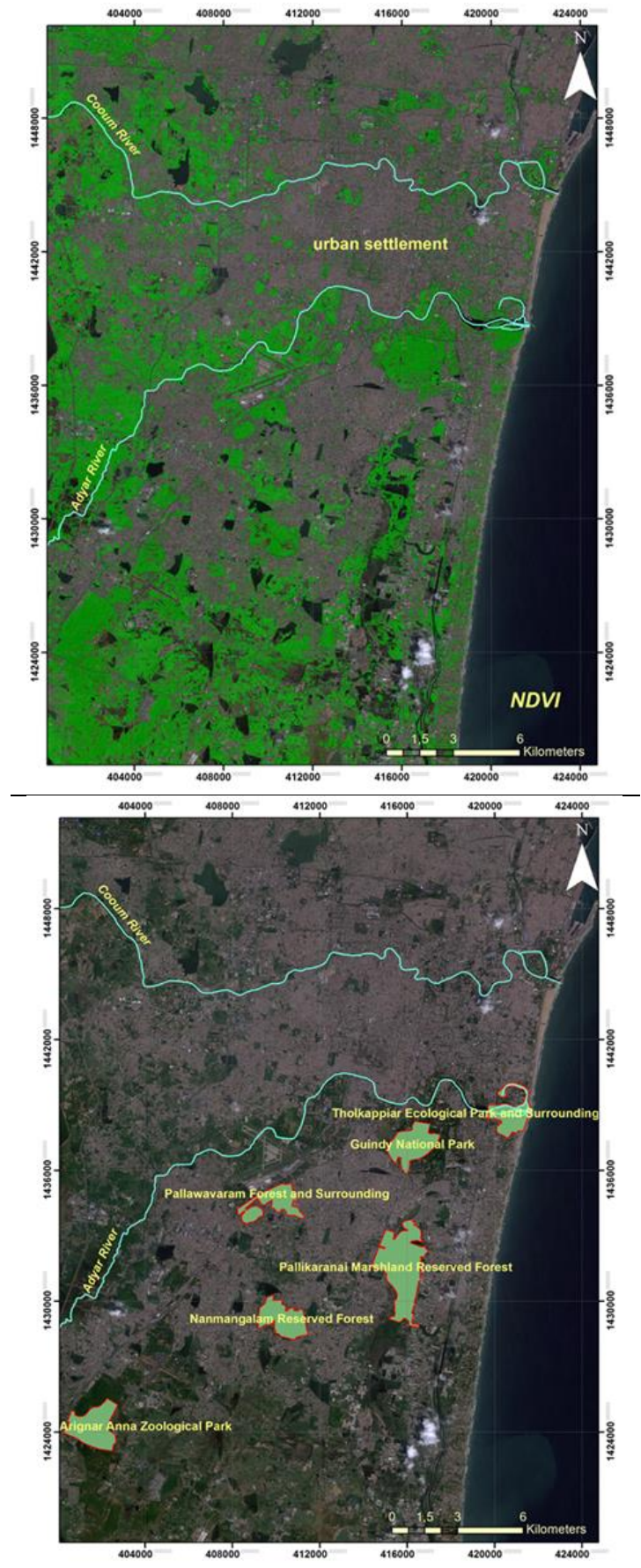

Figure 2. Normalized Difference Vegetation Index of Chennai Around, Selected ecological areas (right)

(1) Guindy National Park, it is the 8th smallest National Park of India, is a protected area of Tamil Nadu, located in Chennai, and one of the rare national city parks. There are more than 350 species of plants, including many trees, shrubs and ground cover plants, and there are wetlands and pastures. There are also 24 varieties of trees. There are over 14 species of mammals and over 150 species of birds (Oppili, P., 2004). (2) Tholkappiar Ecological Park (also known as Adyar Poonga or Tholkappia Poonga) set up by the Government of Tamil Nadu in the Adyar estuary area of Chennai, India. About 50 percent of the park is covered by water. A total of 143 species of fish, amphibians, birds, and reptiles have been 
seen in the park (Lopez, 2011). (3) The Arignar Anna Zoological Park is located at Vandalur in the southwestern part of the Chennai Metropolitan Area known as the Vandalur Zoo that is located within an open green area of more than 500 hectares). (Urban Green Belt, 2016). The zoo is located within the Vandalur Reserve Forest area. The zoo's ecosystem consists of dry deciduous and dry evergreen scrub forest vegetation of the Eastern Ghats (Wikipedia, 2016). (4) Pallikaranai Marshland Reserved Forest, one of the last remaining natural wetlands in the city collects flood water and increases ground water levels in landscape (Bhaskar et al.,, 2011). An extensive low-lying area covered by a mosaic of aquatic grass species, scrub, marsh, and water-logged depressions. (5) Nanmangalam Reserved Forest is a protected area located in the southern part of Chennai, about $24 \mathrm{~km}$ from the city center. It is a scrubland and is home to some of the rare territorial orchids (Padmanabhan, 2016). (6) Pallavaram is a residential locality in Chennai and a selection-grade municipality located in the Metropolitan city of Chennai. The Pallavaram forest, surrounded by settlements, is isolated from other ecological areas. Although it is a small area, it contains aquatic and terrestrial plant and animal species.

Other research materials used in the study are written and visual documents about Chennai, Sentinel 2 satellite images dated 03.10.2016 and cloudiness \% 0,001, ArcGIS 10.1, QGIS 2.18 and Conefor Sensinode 2.2 software's (Table 1).
Table 1. Sentinel 2 used bands and features

\begin{tabular}{lll}
\hline $\begin{array}{l}\text { Sentinel-2 } \\
\text { Bands }\end{array}$ & Wavelength & Resolution \\
\hline Blue & $0.490 \mu \mathrm{m}$ & $10 \mathrm{~m}$ \\
Green ( & $0.560 \mu \mathrm{m}$ & $10 \mathrm{~m}$ \\
Red & $0.665 \mu \mathrm{m}$ & $10 \mathrm{~m}$ \\
NIR & $0.842 \mu \mathrm{m}$ & $10 \mathrm{~m}$ \\
\hline
\end{tabular}

\subsection{Method}

The method has four main processing stages (1) A comprehensive database is created for Chennai in the GIS (Fig. 3). At this step, Sentinel II satellite images were downloaded, 4-3-2 band combinations were prepared and a base map was created. The ecological, social and cultural data of the research area have been obtained in the direction of literature and related institutions and organizations. (2) At this stage, large habitat patches that affect the city ecologically, socially and culturally have been identified and digitized. (3) At the end of the method, connectivity indices (especially IIC and PC) were used and analyzed to measure the quality and linkages of large habitat patches.

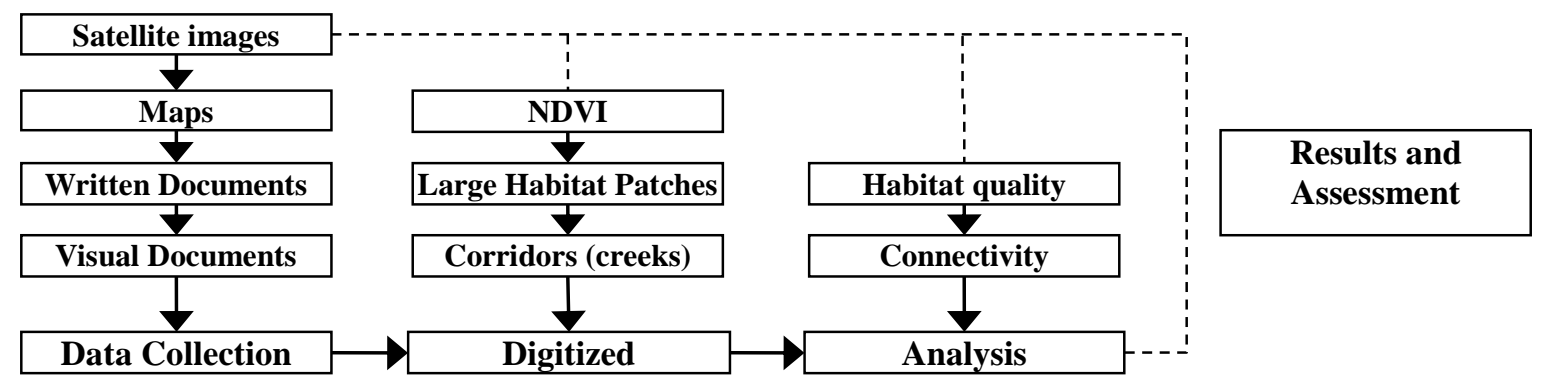

Figure 3. Method flowchart

After the analysis phase, four indices of Conefor software have been used to determine habitat quality and connectivity. These metrics are defined in Table 2 . These indices are more preferred for landscape planning and conservation than other existing indices and these indices are important in defining critical habitat patches and landscape connectivity (Saura and Pascual-Hortal 2007) as shown in Table 2.

Table 2. Metrics and properties used in the study landscape changes (Saura and Pascual-Hortal 2007).

\begin{tabular}{lll} 
Index & Definition & Measuring \\
\hline dA & $\begin{array}{l}\text { This index will be used to analyze the extent to } \\
\text { which the sequences provided by different } \\
\text { topological indices differ from the priorities used } \\
\text { to obtain basic patch characteristics such as } \\
\text { habitat area and habitat quality. (Baranyi et all, }\end{array}$ & $\begin{array}{l}\text { Values close to each other may } \\
\text { show similar patches, especially in } \\
\text { the shape area. When the area of a } \\
\text { habitat patch increases, the quality } \\
\text { also increases relatively. }\end{array}$ \\
\hline This index is used to assess the frequency with & $\begin{array}{l}\text { The shortest paths between all pairs } \\
\text { of patches are summed to calculate } \\
\text { how many patches exist between all } \\
\text { given patch, to determine how much a patch } \\
\text { contains the current flow of the organism. } \\
\text { (Baranyi et all, 2011) }\end{array}$ & $\begin{array}{l}\text { patches with high BC values are } \\
\text { proposed to form the spine of the } \\
\text { landscape. (Saura and Pascual- } \\
\text { Hortal 2007). }\end{array}$
\end{tabular}


This index is a graph-based habitat availability metric that quantifies functional connectivity (Saura and Pascual-Hortal 2007). A habitat availability (reachability) index taking into account varying probabilities of direct dispersal (pij) between different pairs of patches (Bodin and Saura, 2010)

This index works similarly to the PC index, but instead of evaluating the probability of scattering across all pairs of patches, this metric uses the probabilities of distribution across all patches.

dIIC (Bodin and Saura, 2010).
PC ranges from 0 to 1 and increases with improved connectivity. When two patches are isolated from each other, $\mathrm{PC}=0$; When two patches are completely connected to each other, $\mathrm{PC}=1$.

IIC ranges from 0 to 1 and increases
with improved connectivity
strength. If direct dispersal between
any patches in the landscape is
assessed as being possible, the link
strength is set to unity. In other
words, it is set to 0 (that is, the
connection is not assigned between
two patches).
two patches).
In particular the PC and IIC indices, are used to comment the connectivity and quality of the determined landscape patches. These indices are calculated as shown in Figure 6. These connectivity indices enhance the quality of other frequently used indices for planning conservation applications of landscape, including their abilities both for adequately reacting to existing landscape changes and for determining the most important habitats for the sustainable of significant landscape connectivity (Pascual-Hortal and Saura 2006, Saura and Pascual-Hortal 2007, Saura and Torne, 2009).

$$
P C=\frac{\sum_{i=1}^{n} \sum_{j=1}^{n} a_{i} \cdot a_{j} \cdot p_{i j}^{*}}{A_{L}^{2}}
$$

Where $\mathrm{n}$ is the number of patches in the current landscape. ai refers to each habitat area, the total landscape area is defined as AL. pij is the probability of a species moving directly from $\mathrm{i}$ to $\mathrm{j}$ (without passing by).The probability pij is calculated based on a negative exponential dispersal kernel.

$$
I I C=\frac{\sum_{i=1}^{n} \sum_{j=1}^{n} \frac{a_{i} \cdot a_{j}}{1+n l_{i j}}}{A_{L}^{2}}
$$

Here, $\mathrm{n}$ is the total landscape patches number, ai and aj are the qualification of patch $\mathrm{i}$ and $\mathrm{j}$, nlij is the shortest path links number between landscape patches $i$ and $j$, and maximum landscape attribute defined as $\mathrm{AL}$. $\quad \mathrm{IIC}=1$ means, habitats spread throughout all landscapes.

After the analysis phase, in order to the sustainability of the city, the determined habitats and linkages were assessed based on landscape ecology, using the numerical data obtained. In the assessment process, the importance of sensitive areas in terms of ecological characteristics was emphasized and supported with obtained data from analysis.

\section{RESULTS}

The first result is the areas and perimeter length of six landscape patches (Tholkappiar Ecological Park and Surrounding, Guindy National Park, Pallikaranai Marshland Reserved Forest, Pallawavaram Forest, and Surrounding, Nanmangalam Reserved Forest, Arignar Anna Zoological Park) (Table 3). The patch with ID 3 has a larger area than the others and therefore has a more ecological impact on the city. But it does not have a compact form, as seen from the perimeter length. In this case, it can be interpreted that the edge effects on the habitat patch are excessive (Forman, 1995). This may be advantageous for external species, creating a disadvantage for internal species. The patch with ID 2 has a partially compact form. Therefore, it is understood that habitat quality is not bad especially when compared to patch 4 (Table 3).

Table 3. Landscape patches and formal sizes

\begin{tabular}{ccrr}
\hline Name & Patch & Shape length $(\mathbf{m})$ & Shape $\mathbf{a r e a}^{\left(\mathbf{m}^{\mathbf{2}}\right)}$ \\
\hline ID & 1 & 11819,6 & 2420852,76 \\
Tholkappiar Ecological Park and Surrounding & 2 & 8485,57 & 2999596,45 \\
Guindy National Park & 3 & 17725,88 & 6368998,11 \\
Pallikaranai Marshland Reserved Forest & 4 & 12567,68 & 2461131,42 \\
Pallawavaram Forest and Surrounding & 5 & 8653,67 & 2739789,50 \\
Nanmangalam Reserved Forest & 6 & 8837,76 & 3392412,95 \\
Arignar Anna Zoological Park & & & \\
\hline
\end{tabular}

The length of the shortest distances between landscape patches is important in terms of connectivity. The shortest distances of each patch with other patches were determined (Table 4). It is understood that land uses between patches are mostly settlement. All patches are surrounded by settlements. So the patches are under concrete pressure and need to be protected. To ensure the sustainability of these patches, buffer zones must be 
created in the impact zone and the pressure must be reduced. Urban eco-zones protect fragmented landscape patches. When the ecological characteristics of the city are taken into consideration, it is clear that the necessity of protecting these landscape patches in the city is obvious (Fig 4). The distances between patches are listed in Table 4.

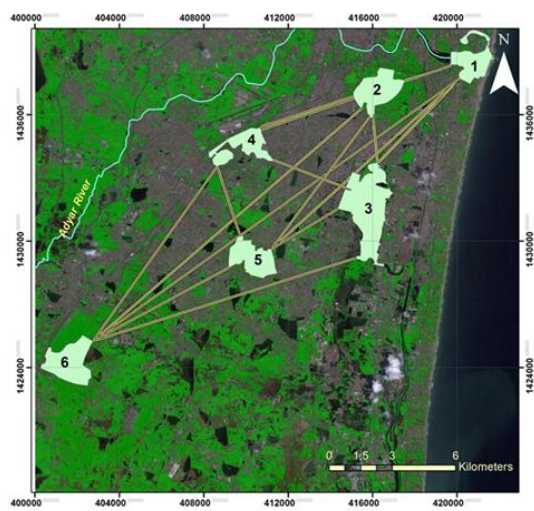

Figure 4. Detected patches and their numbers

Table 4. Shortest distances between the patches

\begin{tabular}{lll|lll}
\hline $\begin{array}{l}\text { Fro } \\
\mathrm{m}\end{array}$ & $\begin{array}{l}\mathrm{T} \\
\mathrm{o}\end{array}$ & $\begin{array}{l}\text { Distance }(\mathrm{m} \\
\text { ) }\end{array}$ & $\begin{array}{l}\text { Fro } \\
\mathrm{m}\end{array}$ & $\begin{array}{l}\mathrm{T} \\
\mathrm{o}\end{array}$ & $\begin{array}{l}\text { Distance }(\mathrm{m} \\
)\end{array}$ \\
\hline 1 & 2 & 2289.90 & 2 & 6 & 16852.90 \\
1 & 3 & 5539.84 & 3 & 4 & 3675.99 \\
1 & 4 & 9453.78 & 3 & 5 & 3678.35 \\
1 & 5 & 12050.45 & 3 & 6 & 13042.51 \\
1 & 6 & 21395.89 & 4 & 5 & 3441.35 \\
2 & 3 & 2727.25 & 4 & 6 & 10139.66 \\
2 & 4 & 4326.38 & 5 & 6 & 7327.02 \\
2 & 5 & 7801.14 & & & \\
\hline
\end{tabular}

\section{DISCUSSION}

Patches 2, 3, 4 and 5 are spread between 1 and 6 patches, and close to each other. The connections between internal patches (id; 2, 3, 4, 5) are short and more influenced by each other ecologically. The longest distance is approximately $21 \mathrm{~km}$ from the patches 1 and 6. The shortest distance is $2127.25 \mathrm{~m}$ from the patches 2 and 3 . The distance between patches is used to interpret the connections of the complex landscape structure. Chennai city has a complex landscape structure. Connectivity analyses of the patches are calculated with the metrics used in the evaluation of complex landscapes (Table 5). Using Conefor Software, it tried to understand landscape ecology with graph theory. The graph theory and the used algorithms show that it is a powerful and effective way to represent landscape structure to make a complex analysis of functionally interconnected patches (Pascual-Hortal and Saura 2006, Pascual-Hortal and Saura 2008).

Table 5. The results of connectivity and quality analysis for selected landscape patches

\begin{tabular}{rllll}
\hline Node & dA & BC & dPC & dIIC \\
\hline 1 & 11.87 & 0.00 & 0.20 & 0.19 \\
2 & 14.71 & 0.03 & 0.29 & 0.25 \\
3 & 31.24 & 0.03 & 0.56 & 0.53 \\
4 & 12.07 & 0.23 & 0.22 & 0.22
\end{tabular}

\begin{tabular}{lllll}
5 & 13.44 & 0.10 & 0.26 & 0.23 \\
6 & 16.64 & 0.00 & 0.23 & 0.24 \\
\hline
\end{tabular}

As regards the dA value of all landscaping patches is assessed, it is seen that patch 3 is different from the others. This difference is the size of the patch. As the landscape patches in the city, it develops ecologically (Forman, 1995). Patch 1 is partly smaller and fed by Adyar River. Adyar River is a natural ecological corridor and positively affects the ecological structure of the route it passes through. It positively increases the ecological characteristics of the city and patch 1 because it is adjacent to the sea.

When $\mathrm{BC}$ value is assessed; In particular, patch 4 , is the backbone of the landscape due to the number of connections. 2, 3 and 5 patches also contribute to urban ecology by providing connections between the determined landscapes. The important point here is the existence of landscape patches due to the city's ecological and socio-cultural structure. This interim patches, improve ecological circulation in the city and provide a positive impact on the city. In particular, these internal patches can be interconnected by rearranging urban ecological corridors (linear items such as main streets and boulevards, etc.) and stimulate urban ecological and cultural life.

The difference of the IIC metric from the similar PC metric is based on networks with weightless connections (Bodin and Saura, 2010).

The combination of PC and IIC metrics is assessed together because it shows the connection requirements of a particular patch and its sensitivity to interruptions and also created corridors are not weighted. IIC is sensitive to the changes in habitat, it helps to understand the connectivity between the landscape elements. On the other hand, PC is more probabilistic, and uses weights, except with these criteria, it is similar to the IIC metric (Gergel and Turner, 2017). The two metrics allows to see how the areas separated and isolation effects (Neel et al., 2014).

In the study, patch 3 is significantly different from the others according to PC and IIC values. It almost got 2 times more points than others. When the ecological characteristics of the city are assessed on the basis of the connection, it is seen that the most important patch is 3 (Pallikaranai Marshland Reserved Forest) for the city. Patches according to importance ratings are listed as 2, 5, 6,4 and 1 . Therefore, this ranking should be taken into account in conservation studies of the Chennai City.

\section{CONCLUSION}

Natural and semi-natural habitats have been dramatically reduced in the region as a result of the distorted urban extension. Despite the negative changes the remnant semi-natural habitat patches still harbor important diversity. It is very important to protect and improve the habitats of this biological diversity. In this study, the ecological connections of important landscapes are defined to protect and improve habitat life in the city. The provision of the connections between the patches is expected to improve the ecological and cultural life of the city.

Saura and Rubio stated in 2010 that the ranking obtained from the connectivity analysis is effective in 
preserving landscapes patches. Bodin and Saura stated in 2010 that IIC, PC and BC metrics jointly assess both the immediate connectivity impacts of the loss of a particular patch and the resulting increased vulnerability of the network to subsequent disruptions. In this study, the integration of different metrics was achieved using a network-based approach while assessing the importance of landscape patches. As we have shown in the study, the multifunctional connectivity can help a related researcher to assess different connectivity aspects of individual patches in an integrated way without being limited to either one of these conceptual assessments. As Baranyi et al., pointed out in 2011, these methods purpose to indicate and rank the relative contribution of landscape patches to the maintenance of connectivity, it is importance to gain a clear understanding their relationships and practical differences for the analysis of fragmented landscape networks. Findings from the study will provide a better understanding of the relationships between landscape patches and it will also contribute to ecological research and applications on the region by revealing the connections and relations between landscape patches.

\section{REFERENCES}

Akar, A , Gökalp, E. (2018). Designing A Sustainable Rangeland Information System For Turkey. International Journal of Engineering and Geosciences 3 (3), 87-97. DOI: $10.26833 /$ ijeg.412222.

Baranyi, G., Saura, S., Podani, J., Jordan, F. (2011). Contribution of habitat patches to network connectivity: Redundancy and uniqueness of topological indices, Ecological Indicators 11, 1301-1310.

Bhaskar, A., Rao, G.B., Vencatesan, J. (2011). Characterization and Management Concerns of Water resources around Pallikaranai Marsh, South Chennai. A Volume in the Advances in Environmental Engineering and Green Technologies Book Series. Chapter 7, 102121.

Bodin, Ö., Saura, S. (2010). Ranking individual habitat patches as connectivity providers: Integrating network analysis and patch removal experiments. Ecological Modelling 221,2393-2405.

Bogyó, D., Magura, T., Simon, E., Tothmeresz, B. (2015) Millipede (Diplopoda) assemblages alter drastically by urbanisation. Landscape and Urban Planning133, 118-126.

Forman, R.T.T. (1995). Land Mosaics, The Ecology of Landscape and Regions, Cambridge University Press, Cambridge, UK, 656p.

Gergel, S.E., Turner, M.G. (2017). Learning Landscape Ecology: A Practical Guide to Concepts and Techniques,Springer, $340 \mathrm{p}$.

Gubta, A.K., Nair, S.S. (2011) Urban floods in Bangalore and Chennai: risk management challenges and lessons for sustainable urban ecology. Current Science 100(11),1638-1645.

Govindarajulu, D. (2014). Urban green space planning for the climate adaptation in Indian cities, Urban Climate, 10(1), 35-41.
Hüse, B., Szabo, S., Deak, B., Tothmeresz, B. (2016). Mapping an ecological network of green habitat patches and their role in maintaining urban biodiversity in and around Debrecen city (Eastern Hungary). Land Use Policy 57, 574-581

IMD (2010). Indian Meteorological Department, Ever Recorded Maximum Temperature, Minimum Temperature and 24 Hours Heaviest Rainfall up to 2010, $67 \mathrm{p}$.

Janakiraman, A., Naveed, M. S., Muthupriya, P., Sugumaran, J., Sheriff, M. A., Altaff, K. (2013). Studies on the zooplankton biodiversity and density in Adyar estuary, Chennai, India. Journal of Environmental Biology 34(2) ,273-275.

Kong, F., Yin, H., Nakagoshi, N., Zong, Y. (2010). Urban green space network development for biodiversity conservation: identification based on graph theory and gravity modeling. Landscape and Urban Planning 95 (12), 16-27.

Kuşçu Şimşek, Ç, Türk, T , Ödül, H , Çelik, M. (2018). Detection Of Paragliding Fields by GIS. International Journal of Engineering and Geosciences 3 (3), 119-125. DOI: $10.26833 /$ ijeg.413833

Lopez, A,X. (2011). More winged visitors flock to Adyar Poonga. The Hindu, Online edition of India's National Newspaper.

Majka, D., Jenness, J., Beier, P. (2007). Corridor Designer: ArcGIS tools for designing and evaluating corridors. http://corridordesign.org/downloads (Access date: 04.01.2017).

Memduhoglu, A , Basaraner, M . (2018). Possible Contributions of Spatial Semantic Methods And Technologies to Multi-Representation Spatial Database Paradigm. International Journal of Engineering and Geosciences 3 (3), 108-118. DOI: 10.26833/ijeg.413473.

MUB (2011). Ministry of Urban Development, Government of India. India Smart City Profile report, 5p.

Neel, M., Tumas, H. R., \& Marsden, B. W. (2014). Representing connectivity: quantifying effective habitat availability based on area and connectivity for conservation status assessment and recovery. PeerJ, 2,e622.doi.org/10.7717/peerj.622

Oppili, P. (2004). Looking for exotic species at the Guindy National Park. The Hindu, Online edition of India's National Newspaper.

Padmanabhan, G. (2016). Chennai's eco spots. The Hindu, Online edition of India's National Newspaper.

Pascual-Hortal, L. and Saura, S. (2006). Comparison and development of new graph-based landscape connectivity indices: towards the priorization of habitat patches and corridors for conservation. Landscape Ecology 21 (7), 959-967.

Pascual-Hortal, L. and Saura, S. (2008). Integrating landscape connectivity in broad-scale forest planning through a new graph-based habitat availability methodology: application to capercaillie (Tetrao urogallus) in Catalonia (NE Spain). European Journal of Forest Research 127, 23-31. 
Saura, S., Estreguil, C., Mouton, C., Rodríguez-Freire, M. (2011). Network analysis to assess landscape connectivity trends: application to European forests (1990-2000), Ecological Indicators 11, 407-416.

Saura, S., Pascual-Hortal, L. (2007). A new habitat availability index to integrate connectivity in landscape conservation planning: comparison with existing indices and application to a case study. Landscape Urban Plan. doi:10.1016/j.landurbplan.2007.03.005.

Saura, S., Rubio, L. (2010). A common currency for the different ways in which patches and links can contribute to habitat availability and connectivity in the landscape". Ecography 33, 523-537.

Saura, S., Torné, J. (2009). Conefor Sensinode 2.2: a software package for quantifying the importance of habitat patches for landscape connectivity. Environmental Modelling \& Software 24,135-139.

Talley, T.S., Fleishman, E., Holyoak, M., Murphy, D.D., Ballard, A. (2007). Rethinking a rare-species conservation strategy in an urban landscape: the case study of a valley elderberry longhorn beetle. Journal of Biological Conservation 135, 21-32.

The Economist (2015). Next time by water. Flood and India's Coromandel Coast, http://www.economist.com/news/asia/21679822-floodsshould-be-warning-those-building-state-capital-scratchnext-time-water. (access date: 02.01.2017).

Thompson, C.W. (2002). Urban open space in the 21st century, Landscape Urban Planning., 60 (1), 59-72.

Urban Green Belt, (2016) http://edugreen.teri.res.in/explore/forestry/urban.htm (access date: 10.07.2018).

Wikipedia, (2016). Chennai. https://en.wikipedia.org/wiki/Chennai (access date: 04.01.2017)

Williams, N.S.G., Schwartz, M.W., Vesk, P.A., McCarthy, M.A., Hahs, A.K., Clemants, S.E., Corlett, R.T., Duncan, R.P., Norton, B.A., Thompson, K., McDonnell, M.J. (2009). A conceptual framework for predicting the effects of urban environments on floras. Journal of Ecology 97, 4-9.

Zipkin, E.F., DeWan, A., Royle, J.A. (2009). Impacts of forest fragmentation on species richness: a hierarchical approach to community modeling. Journal of Applied Ecology 46, 815-822. 